\title{
Shape Changes Induced by N-Terminal Platination of Ubiquitin by Cisplatin
}

\author{
Jonathan P. Williams, ${ }^{\mathrm{a}, *}$ Hazel I. A. Phillips, ${ }^{\mathrm{a}}$ Iain Campuzano, ${ }^{\mathrm{b}}$ and \\ Peter J. Sadler ${ }^{\mathrm{a}}$ \\ ${ }^{a}$ Department of Chemistry, University of Warwick, Coventry, United Kingdom \\ ${ }^{\mathrm{b}}$ Waters Corporation, Manchester, United Kingdom
}

\begin{abstract}
The three-dimensional conformation of a protein is an important property and plays a key role in its biological activity. We show here that ion mobility-mass spectrometry (IM-MS) can be used to detect conformational changes in the protein ubiquitin in the gas phase induced by reaction with the anticancer drug cisplatin. The primary adduct was ubiquitin- $\left\{\mathrm{Pt}\left(\mathrm{NH}_{3}\right)_{2}\right\}$ under denaturing conditions. Up to three different conformations appear to be generated upon platination depending on the charge state. The collision cross-sections $(\Omega)$ for each conformation indicate that the conformations of the platinated protein are contracted in size compared with unmodified ubiquitin with generally smaller $\Omega$ values. Ion mobility-tandem MS allowed determination of the platinum binding site without a requirement for prior chromatographic separation. A rapid 30-min digestion of cisplatin-modified ubiquitin with trypsin allowed the platination site to be identified as the N-terminal methionine following low-energy collisioninduced dissociation (CID) studies of the modified peptide. The data were generated using a Traveling-Wave based ion mobility-MS approach. Such cisplatin-induced shape changes may have a significant effect on its function in vivo. This work highlights the usefulness of the ion-mobility mass spectrometry technique for shedding new light on such protein interactions. (J Am Soc Mass Spectrom 2010, 21, 1097-1106) () 2010 Published by Elsevier Inc. on behalf of American Society for Mass Spectrometry
\end{abstract}

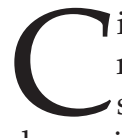
isplatin, cis- $\left[\mathrm{PtCl}_{2}\left(\mathrm{NH}_{3}\right)_{2}\right]$, and other platinum-containing drugs have become extremely successful and widely used as anticancer drugs in the clinic, particularly for the treatment of ovarian, testicular, head, and neck cancers [1]. While its interaction with DNA is considered to be the key event for exerting its toxic effect in cancer cells [2, 3], cisplatin can also readily interact with a number of potential protein and peptide targets in the body. It has been previously found that within $24 \mathrm{~h}, 65 \%-90 \%$ of the administered platinum is bound to proteins in blood plasma [4]; such platinum-protein interactions reduce the level of excreted platinum and increase the deposition of platinum in tissues [5]. Such reactions may contribute to the toxic side-effects exhibited in patients, especially nephrotoxicity and hearing loss [6], but may also contribute the mechanism of cancer cell toxicity.

Ion mobility-mass spectrometry (IM-MS) has been used extensively to interrogate complex biomolecules (e.g., DNA, proteins) in the gas phase [7-14], yielding useful information concerning their conformation and structure. This technique could also be applied to probe

Address reprint requests to Dr. J. P. Williams or Prof. Dr. P. J. Sadler, Department of Chemistry, University of Warwick, Coventry, CV4 7AL, United Kingdom. E-mail: Jonathan_Williams@waters.com or P.J.Sadler@ warwick.ac.uk

* Present address: Waters Corporation, Manchester, United Kingdom. the potential structural changes caused by drugs, to further understand their biological implications in vivo. The small, highly conserved protein ubiquitin (UBQ, average molecular weight $8564.9 \mathrm{Da}$ ) plays a crucial role in ubiquitination pathways and has direct and indirect roles in tumor propagation [15]; it is therefore a potential drug target in cancer cells. Cisplatin has been shown to have inhibitory effects on the ubiquitination process of proteins in vitro [16] and it is therefore of relevance to investigate not only the platinum binding site(s) on ubiquitin but also any induced conformational changes.

There are many reports of studies of reactions of platinum complexes with proteins, including cytochrome $c$, human serum albumin (HSA), metallothionein, and $\gamma$-globulin [17-21], using various techniques such as flameless atomic absorption spectroscopy (FAAS), UV-Vis spectroscopy, 1D ${ }^{1} \mathrm{H}$ NMR, and 2D inverse detection $\left[{ }^{1} \mathrm{H}^{15} \mathrm{~N}\right]$ HSQC NMR studies using ${ }^{15} \mathrm{~N}$-enriched cisplatin. In particular, a number of reports have focused on the reaction of cisplatin with UBQ [22-25]. In one previous study, it was concluded that the primary binding site for cisplatin on UBQ is the $\mathrm{N}$-terminal methionine residue [22]. Oxidation of Met1 significantly reduced its reactivity towards cisplatin but it was not possible to isolate and characterize a platinated peptide resulting from trypsin digestion of the protein. Further support for Met1 as the primary bind-
(C) 2010 Published by Elsevier Inc. on behalf of American Society for Mass Spectrometry. $1044-0305 / 10 / \$ 32.00$

doi:10.1016/j.jasms.2010.02.012
Published online February 11, 2010 Received December 3, 2009 Revised February 4, 2010 Accepted February 8, 2010 
ing site has come from recent studies using an intact tandem FT-ICR-MS (top-down MS) approach [25], which allowed detection of a platinated peptide ion of sequence $\left[{ }^{1} \mathrm{MQIF}{ }^{4}+\mathrm{Pt}-2 \mathrm{H}\right]^{+}$.

Here, we have investigated the binding of cisplatin to UBQ using a traveling-wave-based ion mobilitytandem mass spectrometry approach. We have investigated induced conformational changes upon platination of intact UBQ, and characterized a platinated peptide product ion following intact tandem MS and a rapid 30-min digestion using trypsin [26]. The location of the platinated amino acid residue was determined by direct analysis of trypsin digested cisplatin-modified UBQ using low-energy collision induced dissociation (CID).

\section{Experimental}

\section{Materials}

Ubiquitin from bovine red blood cells was purchased from Fluka (Dorset, UK) and used without further purification. Cisplatin (CDDP) was synthesized according to literature methods [27]. Acetonitrile (HPLC grade) and water (HPLC grade) were purchased from Fisher Scientific (Loughborough, UK). Formic acid and trypsin were purchased from Sigma Aldrich (T 1426; Sigma-Aldrich Corp., St Louis, MO, USA), and ammonium acetate was purchased from Fluka.

\section{Reaction Between UBQ and Cisplatin}

Aqueous solutions of UBQ $(1 \mathrm{mg} / \mathrm{mL})$ and the platinum complex cisplatin $(1 \mathrm{mM})$ were prepared and mixed to give a protein:platinum complex molar ratio of $1: 10$. The samples were incubated at $37^{\circ} \mathrm{C}$ for $24 \mathrm{~h}$, and then centrifuged either using pre-washed Centricon YM-3 filters (MW cut off $=3 \mathrm{kDa}$ (Millipore, Watford, UK)) at 7000 RPM for $2 \mathrm{~h}$ at $4{ }^{\circ} \mathrm{C}$, or Amicon Ultra filters (MW cut off $=3 \mathrm{kDa}$ (Millipore, Watford, UK)) at $7500 \mathrm{RPM}$ for $1 \mathrm{~h}$ at $4{ }^{\circ} \mathrm{C}$, to remove unbound platinum, and washed twice with $1 \mathrm{~mL}$ water. Samples were then diluted as appropriate to a concentration of $10 \mu \mathrm{M}$, before MS analysis.

\section{Tryptic Digestion Protocol}

In summary, a $100 \mu \mathrm{L}$ aliquot of the stock solution [either $100 \mu \mathrm{M}$ UBQ or $100 \mu \mathrm{M}$ UBQ + Cisplatin (1:10)] was denatured by adding $20 \mu \mathrm{L} \mathrm{50 \%}$ aqueous acetonitrile with $0.5 \%$ formic acid (vol/vol). A $6 \mu \mathrm{L}$ aliquot of ammonium bicarbonate $(1 \mathrm{M})$ and $5 \mu \mathrm{L}$ trypsin (5 $\mathrm{mg} / \mathrm{mL}$ ) were then added, and the resulting solution incubated for $30 \mathrm{~min}$ at $37^{\circ} \mathrm{C}$. The solution was then diluted tenfold with 5:4 acetonitrile:water with $0.2 \%$ formic acid before MS analysis.

\section{Ion Mobility-Mass Spectrometry}

ESI-MS was performed on a Traveling-Wave based ion mobility-mass spectrometer, the Synapt (High Definition Mass Spectrometer) HDMS (Waters Corporation, Manchester, UK) [28]. The ion mobility section comprises three consecutive, gas filled, traveling wave (T-Wave) rf ion guides. Ions are accumulated in the first (Trap) T-Wave and periodically released into the second (Mobility cell) T-Wave, where they separate according to their mobility through action of a continuous train of transient DC voltage pulses (traveling waves). The separated ions are then propelled through the third (Transfer) T-Wave into the oa-TOF analyzer for mass analysis.

The instrument was operated with a capillary voltage of $3.0 \mathrm{kV}$. The ion source block and nitrogen desolvation gas temperature were set to 80 and $100^{\circ} \mathrm{C}$, respectively. The Trap and Transfer T-Wave sections were operated at $\sim 2.3 \times 10^{-2}$ mbar of sulphur hexafluoride $\left(\mathrm{SF}_{6}\right)$, and the ion mobility T-Wave at 3.0 mbar of helium. The Mobility T-Wave was operated with a velocity of $250 \mathrm{~m} / \mathrm{s}$ and the pulse height optimized between 7 and $9 \mathrm{~V}$. The HDMS spectra were obtained in ' $\mathrm{V}$ ' mode operating with $\sim 10,000$ full width half maximum (FWHM). All mass spectra were acquired in positive-ion mode. Data acquisition and processing were carried out using MassLynx (Waters Corporation, Manchester, UK) (ver. 4.1) software supplied with the instrument. The systematic approach taken here, as with previous studies which have been comprehensively discussed [29-37], was to calibrate the T-Wave ion mobility device with species of known collision cross-section $(\Omega)$ determined using standard drift tube instruments [38]. Where single charged $\Omega$ values are reported, the mobility T-Wave was calibrated with ions formed from a tryptic digest of human hemoglobin. Multiply charged ions of sperm whale myoglobin and ubiquitin with known $\Omega$ values were used to calibrate the mobility T-Wave where $\Omega$ values for multiply charged ions of cisplatin-modified UBQ are reported.

\section{Results}

A typical mass spectrum of a $10 \mu \mathrm{M}(50 \%$ aqueous acetonitrile containing $0.1 \%$ formic acid) cisplatin-modified UBQ solution obtained using direct infusion $(4 \mu \mathrm{L} / \mathrm{min})$ is shown in Figure 1a. Charge states were detected for both unmodified and cisplatin-modified UBQ ranging from $9+$ to $5+$ over the $m / z$ acquisition range shown. The base peak in the mass spectrum is that of unmodified UBQ, $[\mathrm{UBQ}+7 \mathrm{H}]^{7+}$. The peak cluster at $\mathrm{m} / \mathrm{z}$ 1256.8 (see inset) indicates the most abundant platinumcontaining adduct of UBQ, i.e., $\left[\mathrm{UBQ}+\left\{\mathrm{Pt}\left(\mathrm{NH}_{3}\right)_{2}\right\}+\right.$ $5 \mathrm{H}]^{7+}$ detected under the specified experimental conditions, along with other mono-, bi- and tri-functional adducts with $\mathrm{UBQ}$, i.e., $\left\{\mathrm{Pt}\left(\mathrm{NH}_{3}\right)\right\},\left\{\mathrm{Pt}\left(\mathrm{NH}_{3}\right)_{2}\left(\mathrm{H}_{2} \mathrm{O}\right)\right\}$, and $\left\{\mathrm{Pt}\left(\mathrm{NH}_{3}\right)_{2} \mathrm{Cl}\right\}$. Figure $1 \mathrm{~b}$ shows the typical Maximum 
(a)

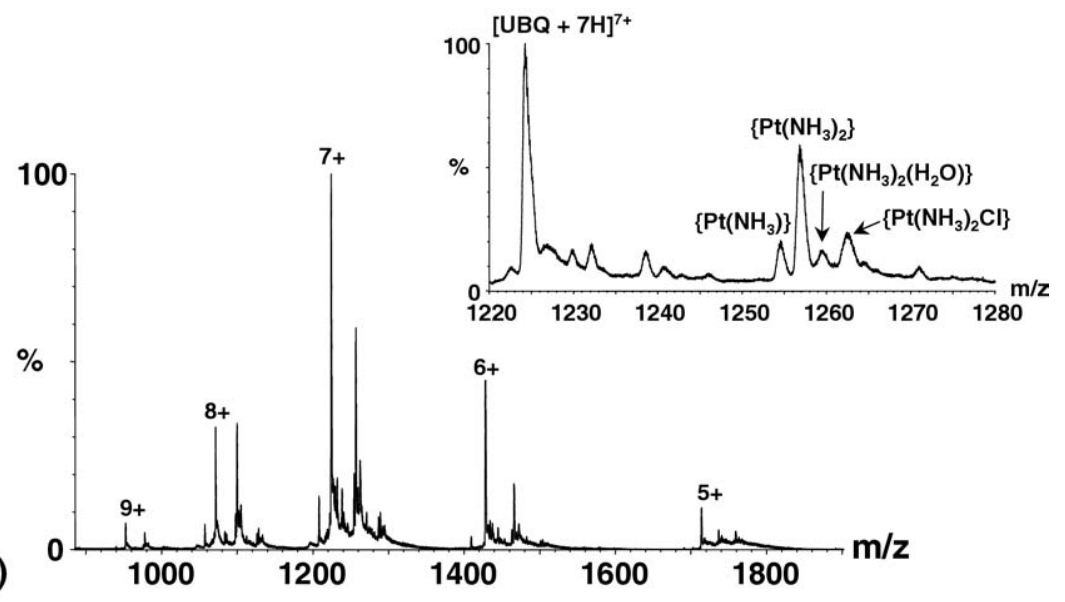

(b)

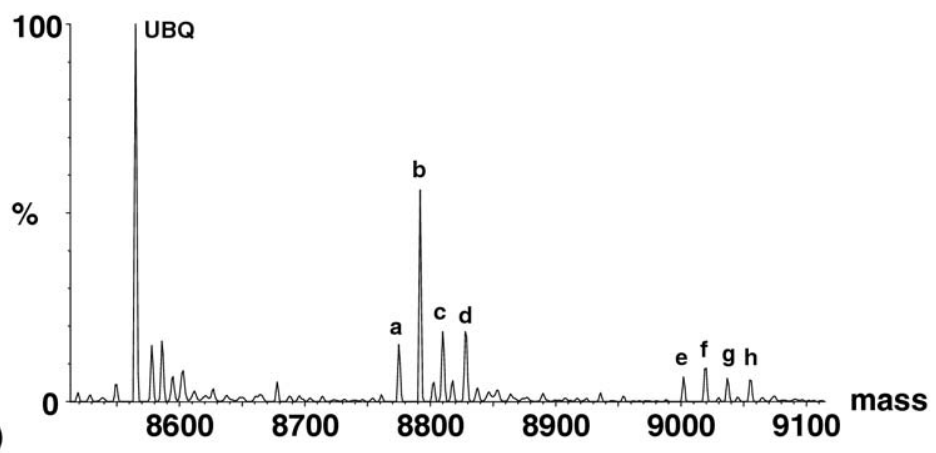

Figure 1. The ESI mass spectrum of denatured UBQ following reaction with cisplatin (1:10) (a) and the maximum entropy deconvoluted ESI mass spectrum containing platinum mono-adducts (labeled $\mathrm{a}-\mathrm{d})$ and bisadducts (labeled e-h) (b) Masses are experimental. The inset shows the +9 charge state, highlighting the different platinum mono-adducts formed.

Entropy deconvoluted ESI mass spectrum of the platinated UBQ. The spectrum contains both mono-adducts (labeled a-d) and also less abundant bisadducts (labeled e-h). The mono-adducts were observed at mass 8775.2, 8792.0, 8810.1, and 8828.4 and are assigned as $\left\{\mathrm{Pt}\left(\mathrm{NH}_{3}\right)\right\},\left\{\mathrm{Pt}\left(\mathrm{NH}_{3}\right)_{2}\right\},\left\{\mathrm{Pt}\left(\mathrm{NH}_{3}\right)_{2}\left(\mathrm{H}_{2} \mathrm{O}\right)\right\}$, and $\left\{\mathrm{Pt}\left(\mathrm{NH}_{3}\right)_{2} \mathrm{Cl}\right\}$ adducts, respectively. The bisadducts (labeled e-h) observed at mass 9002.1, 9019.5, 9037.2, and 9055.5 are ascribed to adducts with $\left\{\mathrm{Pt}\left(\mathrm{NH}_{3}\right)+\right.$ $\left.\operatorname{Pt}\left(\mathrm{NH}_{3}\right)_{2}\right\},\left\{\mathrm{Pt}\left(\mathrm{NH}_{3}\right)_{2}+\operatorname{Pt}\left(\mathrm{NH}_{3}\right)_{2}\right\},\left\{\mathrm{Pt}\left(\mathrm{NH}_{3}\right)_{2}+\mathrm{Pt}\left(\mathrm{NH}_{3}\right)_{2}\right.$ $\left.\left(\mathrm{H}_{2} \mathrm{O}\right)\right\}$, and $\left\{\mathrm{Pt}\left(\mathrm{NH}_{3}\right)_{2}\left(\mathrm{H}_{2} \mathrm{O}\right)_{2}\right\}_{2}$ or $\left\{\mathrm{Pt}\left(\mathrm{NH}_{3}\right)_{2} \mathrm{Cl}+\right.$ $\left.\mathrm{Pt}\left(\mathrm{NH}_{3}\right)_{2}\right\}$, respectively. All of these observed adducts are consistent with previous data obtained for the same system $[22,24]$.

Figure 2 shows an overlay of the observed arrival time distributions (ATDs, or ion mobility drift times) for unmodified UBQ (black line), with the bi- and monodentate cisplatin-modified UBQ adducts $\{\mathrm{UBQ}+$ $\left.\operatorname{Pt}\left(\mathrm{NH}_{3}\right)_{2}\right\}$ (red line) and $\left\{\mathrm{UBQ}+\operatorname{Pt}\left(\mathrm{NH}_{3}\right)\right\}$ (blue line) under denaturing conditions for the charge states $9+$ (a), $8+($ b) and $7+(\mathrm{c})$, respectively. Referring first to unmodified UBQ, some of the ATDs showed evidence of multiple conformational states. For example, although $[\mathrm{UBQ}+9 \mathrm{H}]^{9+}$ appears to have a single conformation, with a single Gaussian peak shape observed in the ATD centered around $4.54 \mathrm{~ms}$, both $[\mathrm{UBQ}+8 \mathrm{H}]^{8+}$ and $[\mathrm{UBQ}+7 \mathrm{H}]^{7+}$ possess more than one conformation (black outline in Figure 2) as is evident by the ATD. Similar observations have previously been reported [38] for the latter two multiply charged ions of unmodified UBQ.

Upon platination, the composite nature of the ATDs of the platinated UBQ species implies that multiple conformations are produced for all charge states. The majority of both platinated species forms were observed to have higher mobilities compared with their unmodified UBQ counterparts with the same charge state, implying a contraction in size. From the measured ion mobility drift times of each multiply charged ion detected, the individual rotationally-averaged T-wave $\Omega$ values for the unmodified and platinated UBQ species were then calculated, and are shown in Table 1 (with helium used as the mobility gas). The published literature $\Omega$ values for UBQ are shown for comparison [12, 39]. To further aid comparison, a plot of the measured $\Omega$ values versus charge state is shown in Figure $2 \mathrm{~d}$. The $\Omega$ values of both the cisplatin-modified UBQ adducts also illustrate a reduction in size of between $2 \%$ and $5 \%$ compared with unmodified UBQ, confirming an overall increase in compactness of the UBQ structure upon platination. This trend is clearly shown for the larger conformers generated for both platinated adducts, 


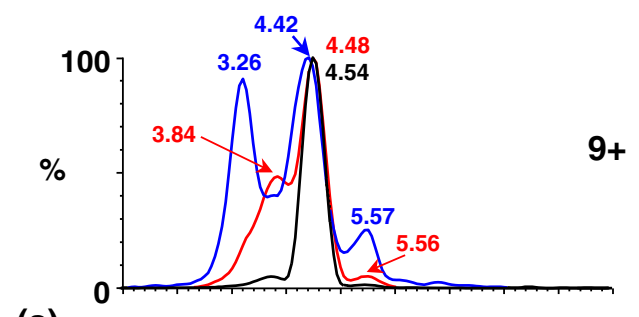

(a)

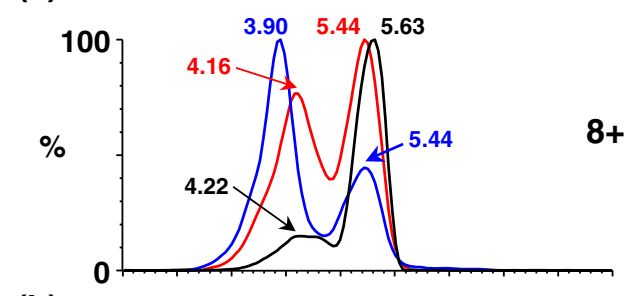

(b)
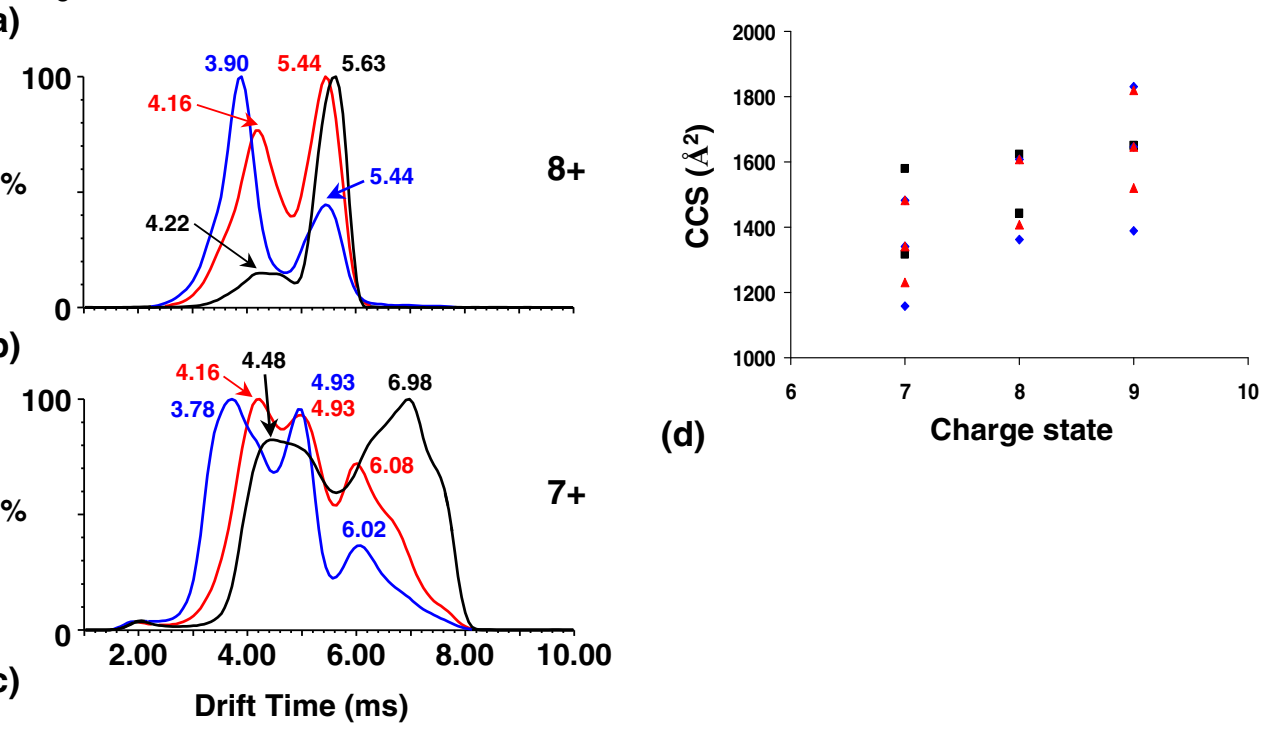

Figure 2. Comparative ATDs of $[\mathrm{UBQ}+7 \mathrm{H}]^{7+},\left[\mathrm{UBQ}+\left\{\mathrm{Pt}\left(\mathrm{NH}_{3}\right)\right\}+5 \mathrm{H}\right]^{7+}$, and $\left[\mathrm{UBQ}+\left\{\mathrm{Pt}\left(\mathrm{NH}_{3}\right)_{2}\right\}+\right.$ $5 \mathrm{H}]^{7+}(\mathbf{a}) ;[\mathrm{UBQ}+8 \mathrm{H}]^{8+},\left[\mathrm{UBQ}+\left\{\mathrm{Pt}\left(\mathrm{NH}_{3}\right)\right\}+6 \mathrm{H}\right]^{8+}$, and $\left[\mathrm{UBQ}+\left\{\mathrm{Pt}\left(\mathrm{NH}_{3}\right)_{2}\right\}+6 \mathrm{H}\right]^{8+}(\mathbf{b}) ;[\mathrm{UBQ}+$ $9 \mathrm{H}]^{9+},\left[\mathrm{UBQ}+\left\{\mathrm{Pt}\left(\mathrm{NH}_{3}\right)\right\}+7 \mathrm{H}\right]^{9+}$, and $\left[\mathrm{UBQ}+\left\{\mathrm{Pt}\left(\mathrm{NH}_{3}\right)_{2}\right\}+7 \mathrm{H}\right]^{9+}$ (c). The black line represents unmodified UBQ $(-)$, the blue line $\left[\mathrm{UBQ}+\left\{\mathrm{Pt}\left(\mathrm{NH}_{3}\right)\right\}\right](-)$, and the red line $\left[\mathrm{UBQ}+\left\{\mathrm{Pt}\left(\mathrm{NH}_{3}\right)_{2}\right\}\right](-)$. Comparison of experimentally derived T-Wave $\Omega$ values for the conformers of [UBQ $+\left\{\mathrm{Pt}\left(\mathrm{NH}_{3}\right)\right\}+$ $(n-2) \mathrm{H}]^{n+}$ (blue diamonds) and [UBQ $\left.+\left\{\mathrm{Pt}\left(\mathrm{NH}_{3}\right)_{2}\right\}+(n-2) \mathrm{H}\right]^{n+}$ (red triangles) obtained under the specified experimental conditions, with published literature values for UBQ (black squares [12, 39] (d).

which have similar reduced $\Omega$ values. However, depending on the charge state, on comparison of the smallest conformer $\Omega$ values generated for the [UBQ + $\left.\left\{\mathrm{Pt}\left(\mathrm{NH}_{3}\right)_{2}\right\}\right]$ and $\left[\mathrm{UBQ}+\left\{\mathrm{Pt}\left(\mathrm{NH}_{3}\right)\right\}\right]$ species (e.g., comparison of $\Omega=1519.724$ and $1389.061 \AA^{2}$, respectively, in the +9 charge state), a further reduction in the $\Omega$

Table 1. T-wave experimentally derived $\Omega$ [or collision cross section values (CCS)] values for cisplatin-modified UBQ adducts of $\left[\mathrm{UBQ}+\left\{\mathrm{Pt}\left(\mathrm{NH}_{3}\right)_{2}\right\}+(n-2) \mathrm{H}\right]^{+}$and $\left[\mathrm{UBQ}+\left\{\mathrm{Pt}\left(\mathrm{NH}_{3}\right)\right\}+\right.$ $(n-2) \mathrm{H}]^{+}$under denaturing conditions at various charge states, with published UBQ $\Omega$ values

\begin{tabular}{cccc}
\hline & \multicolumn{3}{c}{ Calculated Cross Section $\left(\mathrm{CCS}, \AA^{2}\right)$} \\
\cline { 2 - 4 } $\begin{array}{c}\text { Charge } \\
(n)\end{array}$ & {$[\mathrm{UBO}]^{+\mathrm{a}}$} & $\begin{array}{c}{\left[\mathrm{UBO}+\left\{\mathrm{Pt}\left(\mathrm{NH}_{3}\right)_{2}\right\}+\right.} \\
(n-2) \mathrm{H}]^{(n)+}\end{array}$ & $\begin{array}{c}{\left[\mathrm{UBO}+\left\{\mathrm{Pt}\left(\mathrm{NH}_{3}\right)\right\}+\right.} \\
(n-2) \mathrm{H}]^{(n)+}\end{array}$ \\
\hline \hline 9 & & 1519.724 & 1389.061 \\
9 & 1649 & 1645.988 & 1645.996 \\
9 & & 1819.914 & 1829.906 \\
8 & 1442 & 1407.936 & 1361.852 \\
8 & 1622 & 1608.027 & 1608.034 \\
7 & & 1231.000 & 1158.783 \\
7 & 1317 & 1340.676 & 1340.683 \\
7 & 1580 & 1481.745 & 1481.752 \\
\hline
\end{tabular}

aReferences $[12,39]$ value of up to $\sim 9 \%$ accompanies the apparent loss of a single ammonia group. It is of interest that this trend is observed for the smallest conformer only and not for the other generated conformers.

A detailed investigation was then performed to locate the platinum binding site. MS-based methods have been previously used in attempts to characterize the exact binding site of cisplatin on UBQ using FT-ICR-MS, following an intact tandem MS (top-down) approach [25]. A product ion was detected at $\mathrm{m} / \mathrm{z} 713.2$ (based on ${ }^{195} \mathrm{Pt}$ ) following tandem MS of the ion at $\mathrm{m} / \mathrm{z} 1096.1$ [UBQ + $\left.\left\{\mathrm{Pt}\left(\mathrm{NH}_{3}\right)\right\}^{2+}+6 \mathrm{H}\right]^{8+}$. Through the use of accurate mass measurement, this ion was characterized as [MQIF + $\{\mathrm{Pt}\}-2 \mathrm{H}]^{+}$, with MQIF (Met-Gln-Ile-Phe) being the first four amino acid residues of the N-terminus of UBQ. The location of the platinated amino acid could not be determined through the intact tandem MS approach.

The reported FT-ICR-MS experiments [25] were initially repeated by performing intact tandem MS on the cisplatin-modified UBQ ion [UBQ $+\left\{\mathrm{Pt}\left(\mathrm{NH}_{3}\right)_{2}\right\}^{2+}+$ $6 \mathrm{H}]^{8+}(\mathrm{m} / \mathrm{z}$ 1099.1) (see Figure 3). As previously observed, upon top-down fragmentation the expected diagnostic platinated- $\mathrm{b}_{4}$ adduct product ion was detected at $m / z 713.2\left(\left[\mathrm{Pt}+\mathrm{H}_{2} \mathrm{~N}-{ }^{1} \mathrm{MQIF}^{4}-2 \mathrm{H}\right]^{+}\right)$. Tandem MS of the precursor ion detected at $m / z 1071.6$ for 


\section{$\left[{ }^{1} \mathrm{MQIF}^{4}+\mathrm{Pt}-2 \mathrm{H}\right]^{+}$}
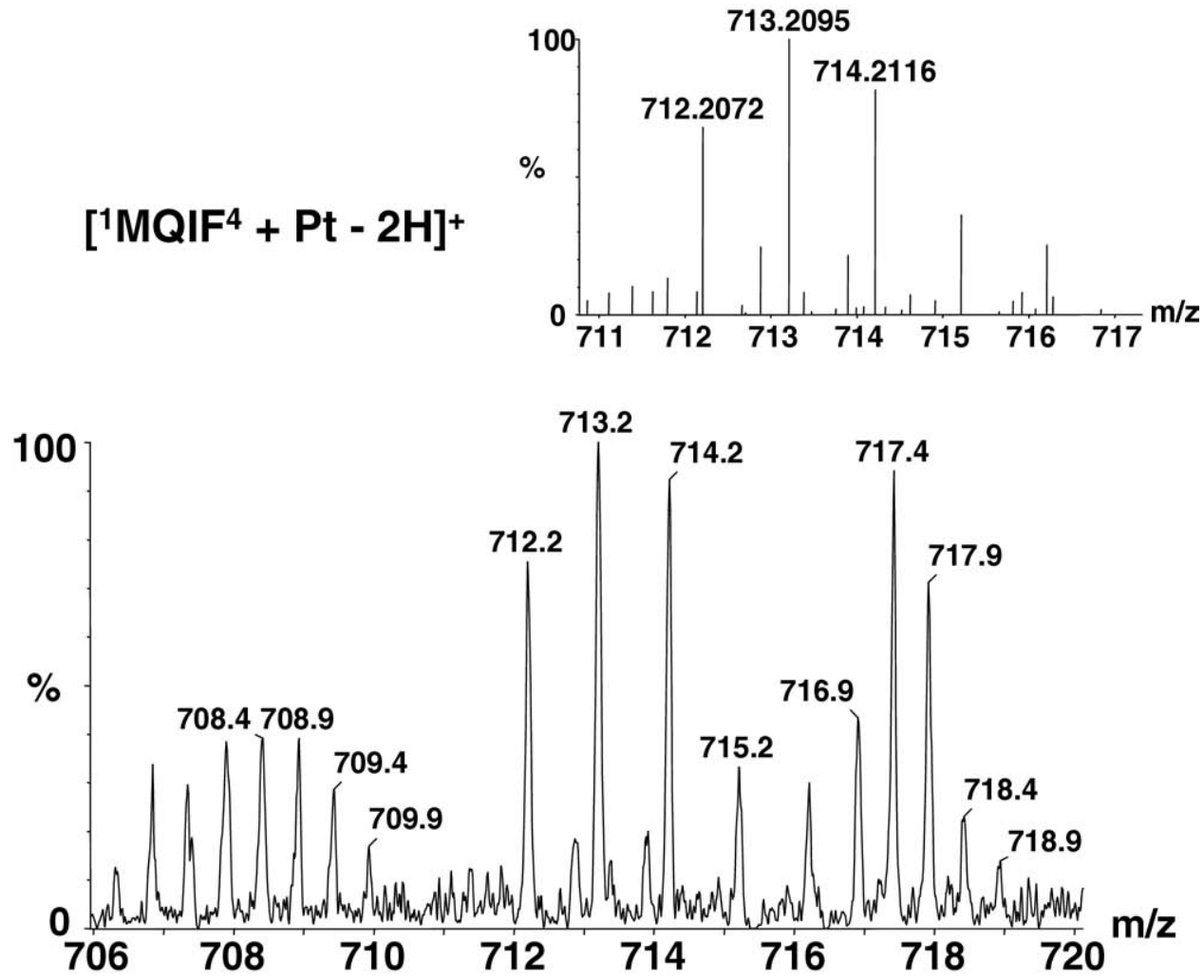

Figure 3. Partial diagnostic tandem MS spectrum obtained following mobility separation of cisplatin-modified UBQ (precursor ion $m / z$ 1100). The inset shows the accurate mass obtained for the diagnostic platinated ion of $\mathrm{m} / \mathrm{z} 713.2$

$[\mathrm{UBQ}+8 \mathrm{H}]^{8+}$ did not show this product. The inset in Figure 3 shows the accurate mass spectrum for the three most intense isotopes in the cluster. The mass resolution afforded by the oa-TOF provided an accurate assignment of an elemental formula for each of the isotopic peaks around $\mathrm{m} / \mathrm{z} 713.2$ (Table 2). The accurate mass measurements are consistent with previous data obtained on the FT-ICR-MS instrument and confirm the identity of the ion as the $\mathrm{b}_{4}\left(\mathrm{C}_{25} \mathrm{H}_{38} \mathrm{~N}_{5} \mathrm{O}_{5} \mathrm{~S}\right)$ adduct with $\{\mathrm{Pt}\}^{2+}$, i.e., $\left[\left(\mathrm{C}_{25} \mathrm{H}_{38} \mathrm{~N}_{5} \mathrm{O}_{5} \mathrm{~S}\right)+\{\mathrm{Pt}\}^{2+}-2 \mathrm{H}\right]^{+}$. No ions containing Pt were detected below $\mathrm{m} / \mathrm{z}$ 712.2. In addition to the MS information, the ATDs of the $b_{4}$ ion and platinated- $\mathrm{b}_{4}$ adduct product ion were measured using T-wave ion mobility, and their individual ro-

Table 2. Accurate mass and elemental formula for the platinated fragmented N-terminal $\mathrm{b}_{4}$ ion $\left({ }^{1} \mathrm{MQIF}^{4}+\{\mathrm{Pt}\}^{2+}-\right.$ $\left.2 \mathrm{H}]^{+}\right)$and platinated $\mathrm{a}_{1}$ methionine immonium ion $\left({ }^{1} \mathrm{M}+\right.$ $\left.\{\mathrm{Pt}\}^{2+}-\mathrm{NH}_{3}\right]^{+}$

\begin{tabular}{cccc}
\hline $\begin{array}{c}\text { Measured } \\
\text { mass }\end{array}$ & $\begin{array}{c}\text { Theoretical } \\
\text { mass }\end{array}$ & $\begin{array}{c}\text { Deviation } \\
\text { (ppm) }\end{array}$ & Generated formula \\
\hline \hline 712.2072 & 712.2064 & 1.1 & $\mathrm{C}_{25} \mathrm{H}_{36} \mathrm{~N}_{5} \mathrm{O}_{5}{ }^{194} \mathrm{Pt}$ \\
713.2095 & 713.2085 & 1.4 & $\mathrm{C}_{25} \mathrm{H}_{36} \mathrm{~N}_{5} \mathrm{O}_{5}{ }^{195} \mathrm{Pt}$ \\
714.2116 & 714.2087 & 4.1 & $\mathrm{C}_{25} \mathrm{H}_{36} \mathrm{~N}_{5} \mathrm{O}_{5}{ }^{196} \mathrm{Pt}$ \\
313.0284 & 313.0270 & 4.5 & $\mathrm{C}_{4} \mathrm{H}_{11} \mathrm{~N}_{2} \mathrm{~S}^{194} \mathrm{Pt}$ \\
314.0279 & 314.0291 & -3.8 & $\mathrm{C}_{4} \mathrm{H}_{11} \mathrm{~N}_{2} \mathrm{~S}^{195} \mathrm{Pt}$ \\
315.0284 & 315.0292 & -2.5 & $\mathrm{C}_{4} \mathrm{H}_{11} \mathrm{~N}_{2} \mathrm{~S}^{196} \mathrm{Pt}$ \\
\hline
\end{tabular}

tationally-averaged $\Omega$ values were determined. The platinated- $\mathrm{b}_{4}$ adduct product ion has a very similar drift time to the $b_{4}$ product ion $(3.33$ and $3.39 \mathrm{~ms}$, respectively) with calculated $\Omega$ values of $158.4 \AA^{2}$ and $158.6 \AA^{2}$, respectively.

At this point, the platination site had still not been unequivocally identified, and consequently a rapid 30min tryptic digest protocol was used on solutions of both UBQ and cisplatin-modified UBQ. Figure 4 shows the partial mass spectra obtained from the tryptic digests of UBQ (a) and cisplatin-modified UBQ (b). The presence of ions $m / \mathrm{z} \sim 210 / 2$ higher than the [UBQT1 + $2 \mathrm{H}]^{2+}$ ion $\left({ }^{1} \mathrm{MQIFVK}^{6}\right.$, Met-Gln-Ile-Phe-Val-Lys, $\mathrm{m} / \mathrm{z}$ 383.2, T1 refers to tryptic peptide 1) in (b) shows, as expected, that platination occurs in this peptide. It should be noted that peak annotation, excluding the diagnostic ions of $\mathrm{m} / \mathrm{z} 383.2$ and 488.7 has been removed for clarity. The inset in Figure 4 shows an expanded view of the doubly-charged isotopic cluster detected at $m / z$ 488.7, corresponding to [UBQT1 $+\left\{\mathrm{Pt}\left(\mathrm{NH}_{3}\right\}-\right.$ $2 \mathrm{H}]^{2+}$. The doubly-charged ions [UBQT1 $\left.+2 \mathrm{H}\right]^{2+}$ (Figure 5a) and [UBQT1 $\left.+\left\{\mathrm{Pt}\left(\mathrm{NH}_{3}\right)\right\}-2 \mathrm{H}\right]^{2+}$ (Figure $5 \mathrm{~b}$ ) were then further sequenced by tandem MS using low-energy CID to determine the platinum binding site. Following CID of the selected platinated precursor ion, C-terminal product ions were detected for $y^{\prime \prime}{ }_{1}-y^{\prime \prime}{ }_{4}$ together with $\left\{\mathrm{y}_{5}{ }_{5}-\mathrm{NH}_{3}\right\}$, with the expected $\mathrm{y}_{5}{ }_{5}$ ion not 


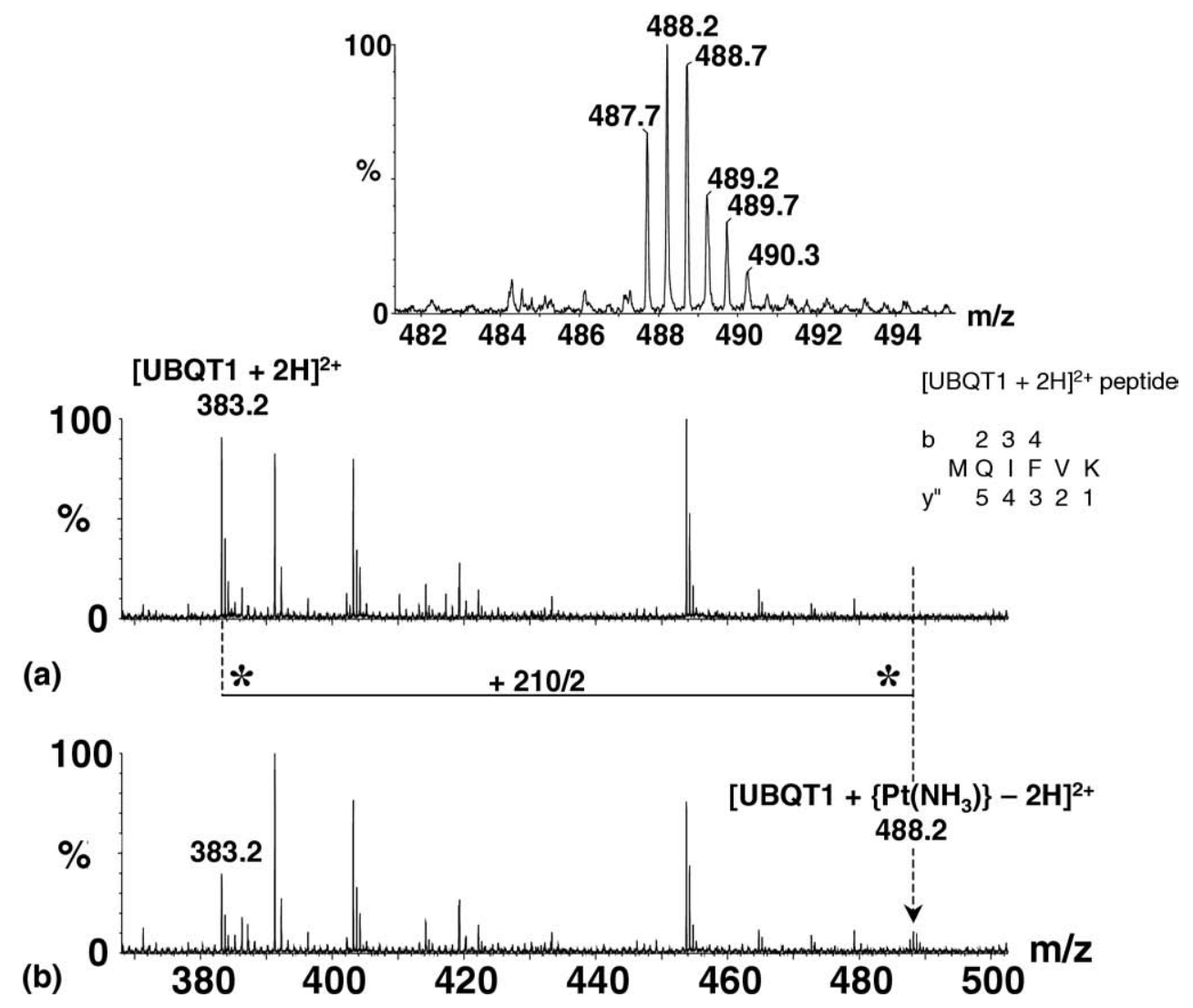

Figure 4. The partial mass spectra of the 30-min tryptic digest of (a) UBQ and (b) cisplatin-modified UBQ. The presence of ions $\mathrm{m} / \mathrm{z} \sim 210 / 2$ higher than the [UBQT1 $+2 \mathrm{H}]^{2+}(\mathrm{MQIFVK}, \mathrm{m} / \mathrm{z} 383.2$, T1 refers to tryptic peptide 1 ) in (b) shows that platination occurs in this peptide. The inset in Figure 4 shows an expanded view of the doubly-charged isotopic cluster detected around $\mathrm{m} / \mathrm{z} 488.7$.

detected. N-terminal platinum-containing product ions were detected for $b_{3}-b_{5}^{+}$, with the platinated $b_{2}^{+}$ion not being detected. Both spectra show immonium ions for methionine and phenylalanine at $\mathrm{m} / \mathrm{z} 104.1$ and 120.1 . Upon fragmentation, the intensity of the methionine immonium ion is reduced following binding of $\left\{\mathrm{Pt}\left(\mathrm{NH}_{3}\right)\right\}^{2+}$. The reverse is found for the phenylalanine immonium ion. A product ion peak was detected at $\mathrm{m} / \mathrm{z}$ 314.0 in (b) but was absent in (a) following tandem MS of the selected precursor ions. This peak is assigned as a platinum adduct of the immonium ion of methionine, methionine- $\left\{\mathrm{Pt}\left(\mathrm{NH}_{3}\right)\right\}$. The mass increase of $210 \mathrm{Da}$ observed between the two spectra places the platinum modification on position 1 , the N-terminal methionine of the modified peptide. The inset shown in Figure 5 shows the accurate mass spectrum for the platinated ion detected at $\mathrm{m} / \mathrm{z}$ 314.0. The accurate mass measured for the immonium ion of methionine detected at $\mathrm{m} / \mathrm{z} 104.0$ was 104.0526. The software-generated elemental formula of $\mathrm{C}_{4} \mathrm{H}_{10} \mathrm{NS}$, showed a deviation of $-7.7 \mathrm{ppm}$ from the theoretical mass of 104.0534. The elemental composition determined for the peaks in the isotope cluster detected around $\mathrm{m} / \mathrm{z} 314$ is also shown in Table 2. These data therefore provide evidence that platination occurs on the N-terminal methionine residue, and represent the first direct observation of this by mass spectrometry-based techniques.

In addition to the MS information, the ion mobility drift times of UBQ [UBQT1 $+2 \mathrm{H}]^{2+}$ and modified UBQ $\left[\mathrm{UBQT1}+\left\{\mathrm{Pt}\left(\mathrm{NH}_{3}\right)\right\}-2 \mathrm{H}\right]^{2+}$ peptide ions were measured using T-wave ion mobility, and their individual rotationally-averaged $\Omega$ values were determined. The modified [UBQT1 $\left.+\left\{\mathrm{Pt}\left(\mathrm{NH}_{3}\right)\right\}-2 \mathrm{H}\right]^{2+}$ peptide ion had a faster drift time compared with the [UBQT1 $+2 \mathrm{H}]^{2+}$ ion suggesting a more compact structure, with $\Omega$ values calculated as $211.4 \AA^{2}$ and $213.4 \AA^{2}$, respectively. It is of interest to note that, as previously observed for the platinated $b_{4}$ ion, a measurable structural distortion can be quantified (although the platinating species is slightly different structurally, i.e., $\left.\left\{\mathrm{Pt}\left(\mathrm{NH}_{3}\right)\right\}^{2+}\right)$.

\section{Discussion}

Cisplatin and other platinum-based drugs are known to have a strong binding preference for sulfur sites in proteins, especially the thioether sulfur of methionine and the thiolate of cysteine. However, although methionine $\mathrm{S}$ is often the kinetically-preferred site (fastest to react), bonds to $\mathrm{N}$ in the imidazole ring of histidine are often stronger and thermodynamically favored. In this 

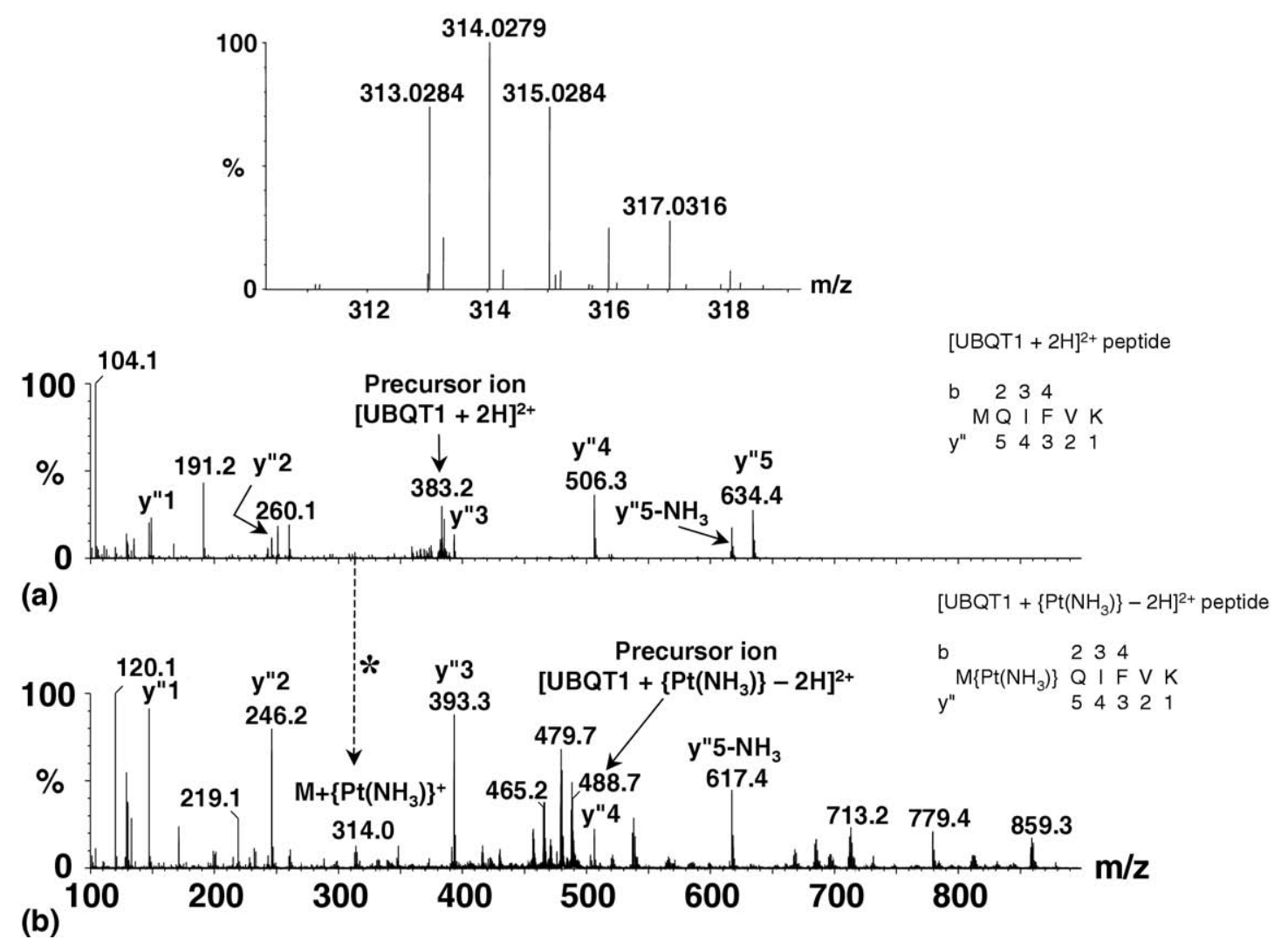

Figure 5. Tandem MS spectra obtained from (a) the unmodified [UBQT1 $+2 \mathrm{H}]^{2+}$ peptide ion (MQIFVK, $m / z$ 383.2) and (b) the cisplatin-modified UBQ [UBQT1 $\left.-\mathrm{Pt}\left(\mathrm{NH}_{3}\right)-2 \mathrm{H}\right]^{2+}$ peptide ion $(\mathrm{m} / z$ 487.7). The 210 Da mass-increase between (a) and (b) upon the methionine immonium ion identifies the platination site. The inset shows the accurate mass measurement of the platinated species of $\mathrm{m} / \mathrm{z} 314$.

work therefore, attention was focused especially on possible binding to Met1 and His68, which are the only Met and His residues present in UBQ [40]. UBQ does not contain any cysteine residues.

Under the denaturing conditions used and by analysis of short tryptic fragments, Met1 has been identified in this study as the primary binding site. This result agrees with previous conclusions based on indirect methods $[22,25]$. The generation of mono [UBQ $+\{\mathrm{Pt}\}]$ adducts can be rationalized on the basis of known platinum(II) chemistry. First, displacement of a chloride leaving group on cisplatin by methionine $S$ is likely to be the first step in the reaction. There are several possibilities for the second step. Aquation of the $\mathrm{Pt}-\mathrm{Cl}$ bond could give a reactive $\mathrm{Pt}-\mathrm{OH}_{2}$ complex, which might be followed by chelate ring formation and displacement of the second $\mathrm{Cl}$ ligand on $\mathrm{Pt}^{\mathrm{II}}$ by the amino terminal nitrogen, giving a six-membered ring, Such chelate formation occurs readily for methionine itself on reaction with cisplatin and related complexes [41, 42]. Another possible second step is liberation of a $\mathrm{NH}_{3}$ ligand due to the large trans effect of the thioether sulfur (weakening of the bond trans to Pt-S in the squareplanar complex) [43,44]. This is more likely to occur under acidic conditions when the liberated $\mathrm{NH}_{3}$ would be readily protonated. Although the initial reactions were carried out at close to neutral $\mathrm{pH}$, formic acid was added during the trypsin digestion step and again to the aqueous acetonitrile solution used for MS analysis. These possible reaction pathways are depicted in Figure 6. Similar pathways have also been discussed by Gibson and Costello [22]. In model systems, it is common for adducts of cisplatin to contain S-bound methionine as the kinetically favored product, but the sulfur can then be displaced by nitrogen from, e.g., the imidazole ring of histidine when there is a competing His residue present. UBQ does contain a His residue, but no transfer from Met1 to His68 was observed under the conditions used $\left(37^{\circ} \mathrm{C}, 24 \mathrm{~h}\right)$.

Although such platination of UBQ (with Pt plus ligands) would be expected to increase the size of the protein and give rise to an increase in its collision cross section, induced structural changes might result in the observed decrease in effective size; for example, chelation of Met1 would restrict the free movement of the flexible N-terminus (as in species b or $\mathrm{j}$ in Figure 6). Gibson and Costello found under initial native conditions that unfolding (or denaturation) of the protein could occur as a consequence of platination, particularly with mono-dentate platinated species [22]; however, in contrast, under the denaturing conditions used in this work, the majority of adducts have smaller 


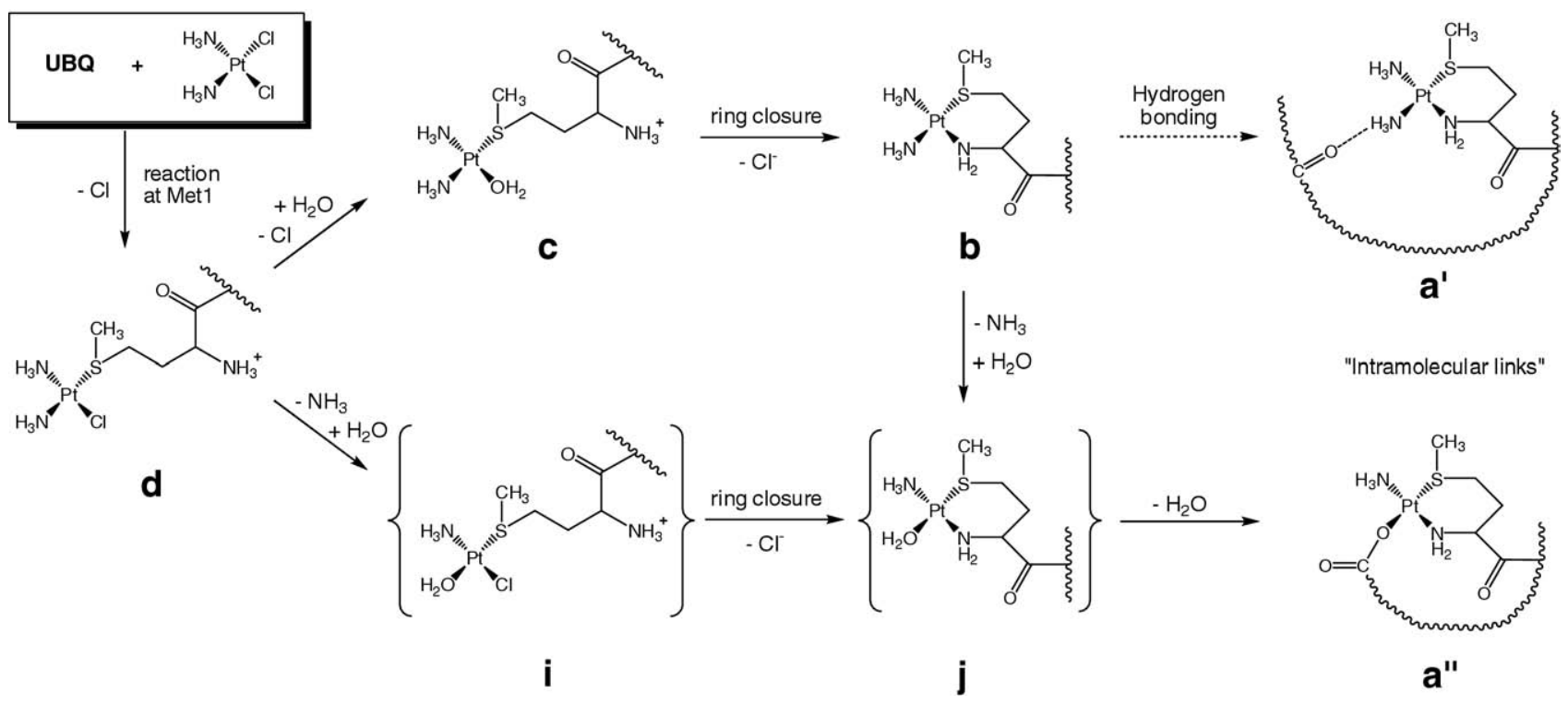

Figure 6. Potential reaction pathways for the formation of platinated mono-adduct products observed in the reaction of cisplatin with ubiquitin (also refer to reference [22] for further details).

protein shapes. The large difference between $\Omega$ values (particularly for the +9 charge state) in the smallest conformer of the mono- and bi-dentate adducts may provide evidence for the so-called "intramolecular link" discussed by Gibson and Costello [22]. Such a link could be formed through interaction with a secondary site on the protein, e.g., through the nearby Glu16 or Glu18 residues (based on crystal structure data [45]). The presence of $\mathrm{Pt}-\mathrm{NH}_{3}, \mathrm{Pt}-\mathrm{OH}_{2}$, or $\mathrm{Pt}-\mathrm{Cl}$ groups in the product provides $\mathrm{H}$-bond donors or acceptor $(\mathrm{Cl})$ that can interact with distant $\mathrm{H}$-bond acceptors (e.g., $\mathrm{C}=\mathrm{O}$ ) or donors (e.g., $\mathrm{NH}, \mathrm{OH}$ ) (species akin to structure $\mathrm{a}^{\prime}$ in Figure 6). Also, upon formation of the Pt-Met chelate, the promoted loss of one of the ammonia ligands could allow formation of a formal bond between platinum and the free carboxylate group of the Glu16/Glu18 side chains (species akin to structure $\mathrm{a}^{\prime \prime}$ in Figure 6). A further possibility that was considered was that upon chelation at the Met site, the promoted loss of one of the ammonia ligands could allow for an interaction of a deprotonated amide $\mathrm{NH}$ site along the peptide backbone. Platinum-induced deprotonation of backbone amide $\mathrm{NH}$ sites has been proposed to occur in peptides and proteins e.g., in the product after reaction of cisplatin with the protein transferrin [46], but tends to occur in X-Met sequences where 6-membered rings can be formed and not at isolated amide $\mathrm{NH}$ sites.

Small structural changes to UBQ may have biological relevance, interfering for example in the second or third UBQ polymeric attachment required for the ubiquitination tagging process, leading to down-regulation of protein ubiquitination and destruction. Isoe et al. have reported that cisplatin can inhibit both ubiquitin-ATPdependent proteolysis and the ubiquitination of proteins through interaction with the enzyme(s) involved in UBQ conjugation, via studies using fraction II from rabbit reticulocyte lysates (which contains ubiquitinATP-dependent protease, E1, E2, and E3 enzymes), but with no apparent interaction with UBQ itself [16]. This result was unexpected, considering the body of literature mentioned in this work on their direct interaction, but the use of a relatively short incubation time in the latter study $(1 \mathrm{~h})$ could account for this observation.

The effect of platination on small peptides produced from direct fragmentation in the MS instrument has also been investigated, with platination of the top-down fragmented $4 \mathrm{aa} \mathrm{b}_{4}$ peptide ion $\left({ }^{1} \mathrm{MQIF}{ }^{4}\right.$ with $\left.\left\{\mathrm{Pt}^{2+}\right\}\right)$ leading to a small but reproducible reduction in the $\Omega$ value, suggesting a more compacted structure. This is of interest since the overall molecular weight of the platinated peptide has increased by $\sim 37 \%$. A similar trend was also found for the platinated 6aa peptide ion after tryptic digest $\left({ }^{1} \mathrm{MQIFVK}^{6}\right.$, UBQT1) with a similar coordinated Pt species $\left(\left\{\mathrm{Pt}\left(\mathrm{NH}_{3}\right)\right\}^{2+}\right)$, where a small reduction in the $\Omega$ value was also observed with an increase in the molecular weight of $\sim 27 \%$.

\section{Conclusions}

T-Wave ion mobility-MS instrumentation was used for determining the binding site of the anticancer drug cisplatin on the protein $\mathrm{UBQ}$, and also to investigate protein shape changes induced by platination. Through this MS study, direct evidence has been obtained to show that platinum is bound to the N-terminal methionine residue. Under the specified experimental conditions and through the use of electrospray ionization, the $\left[\mathrm{UBQ}+\left\{\mathrm{Pt}\left(\mathrm{NH}_{3}\right)_{2}\right\}\right]$ mono-adduct was found to be the most abundant species following a $24 \mathrm{~h}$ reaction between cisplatin and UBQ (1:10, molar ratio). Ion mobility-intact tandem MS offers the advantage that overlapping ionic species can be mobility-resolved before generating the 
tandem MS spectrum. We employed a rapid 30-min tryptic digestion protocol for determining the location of platinum in the platinum-containing fragments. The digestion protocol is highly reproducible with MS evidence directly indicating that the platinated moiety remains attached to the UBQ following digestion. This approach does not require any prior chromatographic separation.

Furthermore, we have calculated $\Omega$ values and determined the effect of platinum binding upon the mobility of UBQ, the $b_{4}$ product ion $\left({ }^{1} \mathrm{MQIF}^{4}\right)$ following intact tandem MS, and also the tryptic peptide T1 $\left({ }^{1} \mathrm{MQIFVK}^{6}\right)$. Our results indicate that although a substantial amount of mass was added through binding of the platinum fragment, the modified structures are more compact in comparison to their unmodified counterparts. These results highlight the fact that small structural distortions upon platination can be measured and quantified in the gas phase using ion mobility on a rapid milli-second timescale. The cross section of the intact protein also appears to contract slightly upon platination, although the number of conformations generated is dependent on the charge state and the attached platinum fragment. Such a shape change may have a significant effect on its function in vivo. Although the distribution of species present in the gas-phase of MS experiments may be different from that present in solution, it is likely the cross sections of the adducts are similar. This work highlights the usefulness of ionmobility mass spectrometry for shedding new light on such protein interactions.

\section{Acknowledgments}

The authors thank the Warwick Research Development Fund for funding a fellowship (J.P.W.), ESPRC and the University of Warwick for a studentship (H.I.A.P.). The authors also acknowledge support from Science City/AWM/ERDF and members of EC COST Action D39 for stimulating discussions.

\section{References}

1. Jamieson, E. R.; Lippard, S. J. Structure, Recognition, and Processing of Cisplatin-DNA Adducts. Chem. Rev. 1999, 99, 2467-2498.

2. Eastman, A. The Mechanism of Action of Cisplatin: From Adducts to Apoptosis. In Cisplatin: Chemistry and Biochemistry of a Leading Anticancer Drug; Lippert, B. Ed.; VCHA and Wiley-VCH: Zurich, 1999; p. 111.

3. Barry, M. A.; Behnke, C. A.; Eastman, A. Activation of Programmed Cell Death (apoptosis) by Cisplatin, Other Anticancer Drugs, Toxins, and Hyperthermia. Biochem. Pharmacol. 1990, 40, 2353-2362.

4. DeConti, R. C.; Toftness, B. R.; Lange, R. C.; Creasey, W. A. Clinical and Pharmacological Studies with cis-Diamminedichloroplatinum(II). Cancer Res. 1973, 33, 1310-1315.

5. Litterst, C. L.; Schweiter, V. G. Increased Tissue Deposition and Decreased Excretion of Platinum Following Administration of Cisplatin to Cisplatin-Pretreated Animals. Cancer Chemother. Pharmacol. 1984, 12, $46-49$

6. Lokich, J.; Anderson, N. Carboplatin Versus Cisplatin in Solid Tumors: An Analysis of the Literature. Ann. Oncol. 1998, 9, 13-21.

7. Gidden, J.; Bowers, M. T. Gas-Phase Conformations of Deprotonated and Protonated Mononucleotides Determined by Ion Mobility and Theoretical Modeling. J. Phys. Chem. B 2003, 107, 12829-12837.

8. Gidden, J.; Ferzoco, A.; Baker, E. S.; Bowers, M. T. Duplex Formation and the Onset of Helicity in Poly d(CG) ${ }_{n}$ Oligonucleotides in a SolventFree Environment. J. Am. Chem. Soc. 2004, 126, 15132-15140.

9. Baker, E. S.; Gidden, J.; Ferzoco, A.; Bowers, M. T. Sodium Stabilization of Dinucleotide Multiplexes in the Gas Phase. Phys. Chem., Chem. Phys. 2004, 6, 2786-2795.
10. Gidden, J.; Baker, E.; Ferzoco, A.; Bowers, M. T. Structural Motifs of DNA Complexes in the Gas Phase. Int. J. Mass Spectrom. 2005, 240, 183-193.

11. Koeniger, S. L.; Clemmer, D. E. Resolution and Structural Transitions of Elongated States of Ubiquitin. J. Am. Soc. Mass Spectrom. 2007, 18 322-331.

12. Valentine, S. J.; Counterman, A. E.; Clemmer, D. E. Conformer-Dependent Proton-Transfer Reactions of Ubiquitin Ions. J. Am. Soc. Mass Spectrom. 1997, 8, 954-961.

13. Wright, P. J.; Zhang, J.; Douglas, D. J. Conformations of Gas-Phase Ions of Ubiquitin, Cytochrome $c$, Apomyoglobin, and $\beta$-Lactoglobulin Produced from Two Different Solution Conformations. J. Am. Soc. Mass Spectrom. 2008, 19, 1913.

14. Myung, S.; Badman, E. R.; Lee, Y. J.; Clemmer, D. E. Structural Transitions of Electrosprayed Ubiquitin Ions Stored in an Ion Trap over $\sim 10 \mathrm{~ms}$ to $30 \mathrm{~s}$. I. Phys. Chem. A 2002, 106, 9976-9982.

15. Hoeller, D.; Hecker, C. M.; Dikic, I. Ubiquitin and Ubiquitin-Like Proteins in Cancer Pathogenesis. Nat. Rev. Cancer 2006, 6, 776-788.

16. Isoe, T.; Haito, M.; Shirai A.; Tsuruo, T. Inhibition of Different Steps of the Ubiquitin System by Cisplatin and Aclarubicin. BBA-Gen. Subjects 1992, 1117, 131-135; Isoe, T.; Haito, M.; Hirai, R.; Tsuruo, T. Inhibition of Ubiquitin-ATP-dependent Proteolysis and Ubiquitination by Cisplatin. Anticancer Res. 1991, 11, 1905-1909.

17. Casini, A.; Gabbiani, C.; Mastrobuoni, G.; Messori, L.; Moneti, G. Pieraccini, G. Exploring Metallodrug-Protein Interactions by ESI Mass Spectrometry: The Reaction of Anticancer Platinum Drugs with Horse Heart Cytochrome c. Chem. Med. Chem. 2006, 1, 413-417.

18. Karotki, A. V.; Vašák, M. Reaction of Metallothionein-3 with Cisplatin and Transplatin. J. Biol. Inorg. Chem. 2009, 14, 1129-1138.

19. Gullo, J.; Litterst, C. L.; Maguire, P. J.; Sikis, B. J.; Holth, D. F.; Woodley, P. V. Pharmacokinetics and Protein Binding of cis-Dichlorodiamine Platinum(II) Administered as a 1-hour or as a 20-hour infusion. Cancer Chemother. Pharmacol. 1980, 5, 21-26.

20. Lázníčková, A.; Lázníček, M.; Květina, J.; Drobník, J. Pharmacokinetics and Plasma Protein Binding of Two Platinum Cytostatics CHIP and CBDCA in Rats. Cancer Chemother. Pharmacol. 1986, 17, 133-136.

21. Ivanov, A. I.; Christodoulou, J.; Parkinson, J. A.; Barnham, K. J.; Tucker, A.; Woodrow, J.; Sadler, P. J. Cisplatin Binding Sites on Human Albumin. J. Biol. Chem. 1998, 273, 14721-14730.

22. Gibson, D; Costello, C. E. A Mass Spectral Study of the Binding of the Anticancer Drug Cisplatin to Ubiquitin. Eur. Mass Spectrom. 1999, 5 , 501-510.

23. Peleg-Shulman, T.; Najajreh, Y.; Gibson, D. Interactions of Cisplatin and Transplatin with Proteins. Comparison of Binding Kinetics, Binding Sites, and Reactivity of the Pt-Protein Adducts of Cisplatin and Transplatin Towards Biological Nucleophiles. J. Inorg. Biochem. 2002, 91, 306-311.

24. Hartinger, C. G.; Ang, W. H.; Casini, A.; Messori, L.; Keppler, B. K Dyson, P. J. Mass Spectrometric Analysis of Ubiquitin-Platinum Interactions of Leading Anticancer Drugs: MALDI versus ESI. J. Anal. At. Spectrom. 2007, 22, 960-967.

25. Hartinger, C. G.; Tsybin, Y. O.; Fuchser, J.; Dyson, P. J. Characterization of Platinum Anticancer Drug Protein-Binding Sites Using a Top-Down Mass Spectrometric Approach. Inorg. Chem. 2008, 47, 17-19.

26. Wild, B. J.; Green, B. N.; Cooper, E. K.; Lalloz, M. R. A.; Erten, S.; Stephens, A. D.; Layton, D. M. Rapid Identification of Hemoglobin Variants by Electrospray Ionization Mass Spectrometry. Blood Cell. Mol. Dis. 2001, 27, 691-704.

27. Dhara, S. C. A Rapid Method for Synthesis of cis- $\mathrm{Pt}\left(\mathrm{NH}_{3}\right)_{2} \mathrm{Cl}_{2}$. Ind. J. Chem. 1970, 8, 193-194.

28. Pringle, S. D.; Giles, K.; Wildgoose, J. L.; Williams, J. P.; Slade, S. E. Thalassinos, K.; Bateman, R. H.; Bowers, M. T.; Scrivens, J. H. An Investigation of the Mobility Separation of Some Peptide and Protein Ions Using a New Hybrid Quadrupole/Traveling Wave IMS/oa-TOF Instrument. Int. J. Mass Spectrom. 2007, 261, 1-12.

29. Ruotolo, B. T: Giles, K. Campuzano, I; Sandercock, A. M. Bateman, R. H.; Robinson, C. V. Evidence for Macromolecular Protein Rings in the Absence of Bulk Water. Science 2005, 310, 1658-1661

30. Wildgoose, J. L.; Giles, K.; Pringle, S. D.; Koeniger, S. L.; Valentine, S. J.; Bateman, R. H. C.; Clemmer, D. E. Proceedings of the 54th Conference of the American Society for Mass Spectrometry; Seattle, WA, May 28-June 1, 2006 (ThP05, 64).

31. Ruotolo, B. T.; Hyung, S. J.; Robinson, P. M.; Giles, K.; Bateman, R. H. C.; Robinson, C. V. Ion Mobility-Mass Spectrometry Reveals Long-Lived, Unfolded Intermediates in the Dissociation of Protein Complexes. Angew. Chem. Int. Ed. 2007, 46, 8001-8004.

32. Ruotolo, B. T.; Benesch, J.; Sandercock, A.; Hyung, S. J.; Robinson, C. V. Ion Mobility-Mass Spectrometry Analysis of Large Protein Complexes. Nat. Protoc. 2008, 3, 1139-1152.

33. Williams, J. P.; Scrivens, J. H. Coupling Desorption Electrospray Ionization and Neutral Desorption/Extractive Electrospray Ionization with a Traveling-Wave Based Ion Mobility Mass Spectrometer for the Analysis of Drugs. Rapid Commun. Mass Spectrom. 2008, 22, 187-196.

34. Williams J. P.; Bugarcic, T.; A: Giles, K.; Campuzano, I; Rodger, P. M. Sadler, P. J. Isomer Separation and Gas-Phase Configurations of Organoruthenium Anticancer Complexes: Ion Mobility Mass Spectrometry and Modeling. J. Am. Soc. Mass Spectrom. 2009, 20, 1119 1122. 
35. Scarff C. A.; Thalassinos, K.; Hilton G. R.; Scrivens, J. H. Traveling Wave Ion Mobility Mass Spectrometry Studies of Protein Structure: Biological Significance and Comparison with X-ray Crystallography and Nuclear Magnetic Resonance Spectroscopy Measurements. Rapid Commun. Mass Spectrom. 2008, 22, 3297-3304.

36. Thalassinos, K.; Grabenauer, M.; Slade, S. E.; Hilton, G. R.; Bowers, M. T.; Scrivens, J. H. Characterization of Phosphorylated Peptides Using Traveling Wave-Based and Drift Cell Ion Mobility Mass Spectrometry. Anal. Chem. 2009, 81, 248-254.

37. Smith, D. P.; Knapman, T. W.; Campuzano, I.; Malham, R. W.; Berryman, J. T.; Radford, S. E.; Ashcroft, A. E. Deciphering Drift Time Measurements from Traveling Wave Ion Mobility SpectrometryMass Spectrometry Studies. Eur. J. Mass Spectrom. 2008, 15, 113-130.

38. Clemmer, D. E. On-Line Cross Section Database of Collision Cross Sections for Singly-Protonated Polyaminoacids. (http://www.indiana.edu/ clemmer/ Research/cross\%20section\%20database/Peptides/polyaminoacid_cs.htm).

39. Clemmer, D. E. On-Line Cross Section Database of Collision Cross Sections of Individual Protein Charge States. (http://www.indiana.edu/ clemmer/ Research/cross $\% 20$ section $\% 20$ database/Proteins/protein_cs.htm).

40. Appleton, T. G. Donor Atom Preferences in Complexes of Platinum and Palladium with Amino Acids and Related Molecules. Coord. Chem. Rev. 1997, 166, 313-359.
41. Murdoch, P.S.; Ranford, J. D.; Sadler, P. J.; Berners-Price, S. J. Cis-trans Isomerization of [bis(L-Methioninato)Platinum]: Metabolite of the Anticancer Drug Cisplatin. Inorg. Chem. 1993, 32, 2249-2255.

42. Wilson, C.; Scudder, M. L.; Hambley, T. W.; Freeman, H. C. Structures of Dichloro[(S)-Methionine-N,S]Platinum(II) and Chloro[glycyl-(S)Methioninato-N,N',S]Platinum(II) Monohydrate. Acta Crystallogr. C: Cryst. Struct. Commun. 1992, C48, 1012-1015.

43. Thomson, A. J.; Williams, R. J. P.; Reslova, S. The Chemistry of Complexes Related to cis-Pt $\left(\mathrm{NH}_{3}\right)_{2} \mathrm{Cl}_{2}$. An Anti-Tumor Drug. In Structure and Bonding; Dunitz, J. D.; Hemmerich, P.; Ibers, J. A.; Jorgensen, C. K.; Neilands, N. B.; Nyholm, Sir R. B.; Reinen, D.; Williams, R. J. P., Eds.; Springer-Verlag: Berlin, 1972; p. 1.

44. Lempers, E. L. M.; Reedijk, J. Reversibility of Binding of CisplatinMethionine in Proteins by Diethyldithiocarbamate or Thiourea: A Study with Model Adducts. Inorg. Chem. 1990, 29, 217-222.

45. Vijay-Kumar, S.; Bugg, C. E.; Cook, W. J. Structure of Ubiquitin Refined at 1.8 A Resolution. J. Mol. Biol. 1987, 194, 531-544.

46. Cox, M. C.; Barnham, K. J.; Frenkiel, T. A.; Hoeschele, J. D.; Mason, A. B.; He, Q. Y.; Woodworth, R. C.; Sadler, P. J. Identification of Platination Sites on Human Serum Transferrin Using ${ }^{13} \mathrm{C}$ and ${ }^{15} \mathrm{~N}$ NMR Spectroscopy. J. Biol. Inorg. Chem. 1999, 4, 621-631. 